\title{
Determination of Mohr-Coulomb Parameters from Nonlinear Strength Criteria for 3D Slopes
}

\author{
Di Wu $\left(\mathbb{D},{ }^{1}\right.$ Yuke Wang $\left(\mathbb{D},{ }^{2}\right.$ Yue Qiu, ${ }^{3}$ Juan Zhang, ${ }^{1}$ and Yukuai Wan ${ }^{4}{ }^{4}$ \\ ${ }^{1}$ College of Architectural Engineering, Qingdao Binhai University, No. 425, West Jialingjiang Road, Qingdao 266555, China \\ ${ }^{2}$ College of Water Conservancy and Environmental Engineering, Zhengzhou University, No. 100, Science Avenue, \\ Zhengzhou 450001, China \\ ${ }^{3}$ State Key Laboratory of Mining Disaster Prevention and Control Co-founded by Shandong Province and the Ministry of Science and \\ Technology, Shandong University of Science and Technology, No. 579, Qianwangang Road, Qingdao 266590, China \\ ${ }^{4}$ Key Laboratory of Ministry of Education for Geomechanics and Embankment Engineering, Hohai University, \\ No. 1, Xikang Road, Nanjing 210098, China
}

Correspondence should be addressed to Di Wu; wudi@qdbhu.edu.cn

Received 21 March 2019; Revised 23 May 2019; Accepted 9 June 2019; Published 11 July 2019

Academic Editor: Federico Guarracino

Copyright (C) 2019 Di Wu et al. This is an open access article distributed under the Creative Commons Attribution License, which permits unrestricted use, distribution, and reproduction in any medium, provided the original work is properly cited.

\begin{abstract}
Many experimental data have illustrated that the strength envelops for soils are not linear. Nevertheless, the linear Mohr-Coulomb (MC) strength parameters are widely applied for the conventional method, software codes, and engineering standards in the slope design practice. Hence, this paper developed the 3D limit analysis for the stability of soil slopes with the nonlinear strength criterion. Based on a numerical optimization procedure written in Matlab software codes, the equivalent MC parameters (the equivalent friction angle and the equivalent cohesion) from the nonlinear strength envelopes were derived with respect to the least upperbound solutions. Further investigations were made to assess the influences of nonlinear strength parameters and slope geometries on the equivalent MC parameters. The presented results indicate that the equivalent MC parameters are closely related to the nonlinear strength parameters. As the inclination angle increases, the equivalent friction angle becomes bigger, but the equivalent cohesion becomes smaller. Besides, 3D effects on the equivalent MC parameters were found to be slight. The presented approach for the determination of MC strength parameters is analytical and rigorous, and the approximate MC strength parameters in the provided design tables can be alternative references for practical use.
\end{abstract}

\section{Introduction}

Strength criterion is critical for all types of materials in the area of slope stability analysis. The strengths of soils and rocks are universally presented by the linear Mohr-Coulomb (MC) failure envelope, which represents the shear strength by two MC strength parameters: the friction angle and the cohesion. The MC strength parameters have been widely applied in the conventional limit equilibrium methods for the calculations of slope safety factors. Besides, the computer codes and engineering standards for slope design are commonly on the base of the MC strength criterion. However, according to the experimental data, many studies have illustrated that the strength envelops for soils and rocks are not linear [17]. Hence, many researchers then utilized some presented nonlinear strength criteria to conduct slope stability analysis (e.g., Charles \& Soares [8]; Zhang \& Chen [9]; Dawson et al. [10]; Yang \& Yin. [11]; Li et al. [12]; Shen \& Karakus [13]; Gao et al. [14, 15]; Zhao et al. [16]; Xu \& Yang [17]). However, these nonlinear failure criteria are not presented in forms of MC strength parameters and they cannot be directly used in practice for slope design.

To solve this problem, many attempts have been made to derive the equivalent MC parameters from nonlinear strength criteria. Hoek and his partners [18-21] have successively devoted themselves to settling this problem for several decades and proposed the widely analytical solutions for average MC parameters from the Hoek-Brown strength envelope. Meanwhile, other researchers also developed the analytical methods to obtain the MC parameters for rock 
masses satisfying the Hoek-Brown strength criteria [22-26]. Besides, Shen et al. [27] presented an approximate analytical method to determine the MC parameters for slope stability assessment based on the Hoek-Brown strength criterion. Yang \& Yin [28] employed the tangential technique into the limit analysis method to evaluate the equivalent $\mathrm{MC}$ parameters for rock slopes with the Hoek-Brown strength envelope. Reviewing the literature, these presented investigations have been made for slopes in rock masses satisfying the Hoek-Brown criteria and the slope stability analysis have been generally conducted in the condition of plain strain. Therefore, it is necessary to carry out the estimation of the MC strength parameters of soils satisfying the nonlinear criteria. Further studies should be done to consider the three dimensional (3D) effects on the determination of $\mathrm{MC}$ parameters.

For slopes in soils, a number of researchers have used a Power-Law (PL) type of nonlinear strength envelope for the evaluation of slope safety (e.g., Charles \& Soares [8]; Zhang \& Chen [9]; Yang \& Yin [11]; Gao et al. [14, 15]; Zhao et al. [16]; Xu \& Yang [17]). To determine the MC strength parameters of soil slopes with the PL failure criterion, this study adopted the tangential method to carry out the 3D limit analysis method for slope stability assessment. The approximate MC strength parameters could be derived with respect to the least upper-bound solutions. Moreover, the influences of nonlinear parameters and slope geometries (the slope inclination and $3 \mathrm{D}$ effect) on the equivalent $\mathrm{MC}$ parameters have been further investigated in this paper.

\section{Estimation of MC Parameters for 3D Soil Slopes}

2.1. PL Strength Criterion and Tangential Method. Since the nonlinear PL failure criterion was firstly proposed by Zhang \& Chen [9] to express the failure envelopes of cohesive soils, numerous researchers have applied this nonlinear criterion into the slope stability analysis [11, 14-17]. For the PL failure criterion, the shear stress $\tau$ on the slope slip surface is expressed in the form of normal stress $\sigma_{n}$, as follows:

$$
\tau=c_{0}\left(1+\frac{\sigma_{\mathrm{n}}}{\sigma_{0}}\right)^{1 / m}
$$

where the parameters $c_{0}, \sigma_{0}$ and $m$ are the nonlinear strength constants of PL failure criterion. As presented in Figure 1, the parameter $c_{0}$ is the initial cohesion as $\sigma_{\mathrm{n}}$ is zero, the parameter $\sigma_{0}$ is the tensile stress as $\tau$ is zero, and the parameter $m$ is the nonlinearity coefficient.

To implement the use of nonlinear strength criteria for slope engineering, the tangential method was originally proposed by Drescher \& Christopoulos [29] to conduct the limit analysis of slope stability. Then, many researchers employed the proposed tangential method to evaluate the slope safety in the $2 \mathrm{D}$ or $3 \mathrm{D}$ conditions $[11,14-17,28]$. Their studies could demonstrate the validity of stability results obtained from

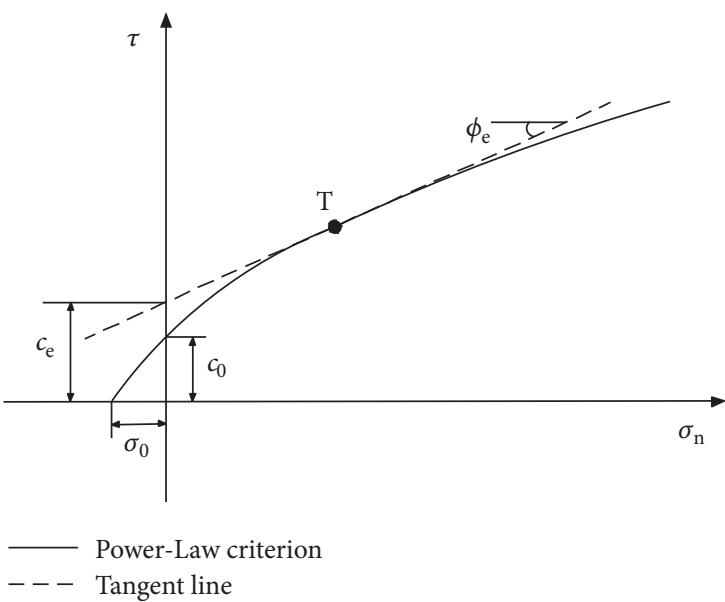

FIGURE 1: PL strength envelope and tangent line.

the tangential method for slope engineering applications. Therefore, the tangential method was also utilized in this study.

As illustrated in Figure 1, the nonlinear strength envelope for certain stress range could be replaced by a tangent line in the form of the equivalent MC strength parameters. At some point $\mathrm{T}$, the expression of the tangent line will be given by the following equation:

$$
\tau=c_{e}+\sigma_{\mathrm{n}} \tan \phi_{e}
$$

where the parameters $\phi_{\mathrm{e}}$ and $c_{\mathrm{e}}$ are the equivalent $\mathrm{MC}$ strength parameters. Here, the parameter $\phi_{\mathrm{e}}$ represents the equivalent friction angle and the parameter $c_{\mathrm{e}}$ represents the equivalent cohesion.

For the PL strength criterion, the gradient of the tangent line at some point $\mathrm{T}$ can be derived from the deviation of the expression of (1) with respect to the normal stress $\sigma_{n}$, as shown in (3).

$$
\tan \phi_{\mathrm{e}}=\frac{\partial \tau}{\partial \sigma_{\mathrm{n}}}=\frac{c_{0}}{m \sigma_{0}}\left(1+\frac{\sigma_{\mathrm{n}}}{c_{0}}\right)^{((1-m) / m)}
$$

By transforming (3), the normal stress $\sigma_{\mathrm{n}}$ can be given in the function of the equivalent friction angle $\phi_{e}$, as follows:

$$
\sigma_{\mathrm{n}}=\sigma_{0}\left(\frac{m \sigma_{0} \tan \phi_{\mathrm{e}}}{c_{0}}\right)^{(m /(1-m))}-\sigma_{0}
$$

Combining this expression with (1), the shear stress $\tau$ can be derived in the form of the equivalent friction angle $\phi_{e}$, that is,

$$
\tau=c_{0}\left(\frac{m \sigma_{0} \tan \phi_{\mathrm{e}}}{c_{0}}\right)^{(1 /(1-m))}
$$


After taking (4) and (5) into (2), the equivalent cohesion $c_{e}$ can be expressed as follows:

$$
\frac{c_{\mathrm{e}}}{c_{0}}=\frac{m-1}{m}\left(\frac{\sigma_{0}}{c_{0}} m \tan \phi_{\mathrm{e}}\right)^{(1 /(1-m))}+\frac{\sigma_{0}}{c_{0}} \tan \phi_{\mathrm{e}}
$$

From (6), it can be seen that the equivalent cohesion $c_{e}$ is a function of the equivalent friction angle $\phi_{e}$. To make indexes being dimensionless, the parameter ratio of $c_{e} / c_{0}$ is used as the equivalent cohesion in this study.

2.2. $3 D$ Limit Analysis. To establish the $3 \mathrm{D}$ limit analysis method, Michalowski \& Drescher [30] and Gao et al. [31] have conducted some researches on the $3 \mathrm{D}$ rotational failure mechanisms for soil slopes considering toe failure, face failure, and base failure. Afterwards, Gao et al. [31] and Gao et al. $[14,15]$ adopted the 3D failure mechanisms for face failure and base failure to present the 3D limit analysis of slope stability based on the MC strength criterion and nonlinear PL strength criterion, respectively. Hence, this study utilized the 3D limit analysis method of Gao et al. [14] to derive the equivalent MC parameters for soil slopes with the PL strength criterion.

As presented by Gao et al. [31], Figures 2(a) and 2(b) give the 3D face failure mechanism and 3D base failure mechanism, respectively. The curvilinear cone can be obtained by rotating a circle with the radius $R$ about an axis. The distance from the axis to the rotation centre $\mathrm{O}$ is defined as the radius $r_{m}$. The expressions of the radiuses $R$ and $r_{\mathrm{m}}$ are presented as follows:

$$
\begin{aligned}
R & =\frac{r-r^{\prime}}{2} \\
r_{\mathrm{m}} & =\frac{r+r^{\prime}}{2}
\end{aligned}
$$

The parameters $r$ and $r^{\prime}$ represent two log-spirals PAD and $\mathrm{PA}^{\prime} \mathrm{D}^{\prime}$ passing through the rotation centre $\mathrm{O}$, which can be expressed as

$$
r=r_{0} \exp \left[\left(\theta-\theta_{0}\right) \tan \phi_{\mathrm{e}}\right]
$$

and

$$
r^{\prime}=r_{0}^{\prime} \exp \left[-\left(\theta-\theta_{0}\right) \tan \phi_{\mathrm{e}}\right]
$$

where the parameters $r_{0}$ and $r_{0}{ }^{\prime}$ represent $\mathrm{OA}$ and $\mathrm{OA}^{\prime}$ in Figure 2 and $\phi_{\mathrm{e}}$ represents the apex angle of curvilinear cone as well as the equivalent friction angle from the PL strength criterion. Figure 3 shows the modified 3D failure mechanisms composed by a curvilinear cone with the width $2 b^{\prime}$ and an insertosome with the width $b$. The ratio of the slope width $B$ to the slope height $H$, namely, the relative width $B / H$, is adopted here to represent the $3 \mathrm{D}$ effect of slopes.
On the basis of the above 3D failure mechanisms, the energy-balance equation can be established by equating the soil weight work rate $W_{\gamma}$ to the internal energy dissipation rate $D$, as shown in the following expression:

$$
W_{\gamma}^{\text {curve }}+W_{\gamma}^{\text {plane }}=D^{\text {curve }}+D^{\text {plane }}
$$

where the parameters $W_{\gamma}^{\text {curve }}$ and $D^{\text {curve }}$ relate to the work rates for the curvilinear cone. The parameters $W_{\gamma}^{\text {plane }}$ and $D^{\text {plane }}$ represent the work rates for the insertosome, which can be seen in the reference of Yang \& Yin [11]. For the curvilinear cone of face failure and base failure, the parameters $W_{\gamma}^{\text {curve }}$ and $D^{\text {curve }}$ will be presented in the following interpretations.

For 3D face failure mechanism (Figure 2(a)), the height of the rotating block is expressed by the parameter $H^{\prime}$. By combining the equivalent strength parameters $\left(c_{e}\right.$ and $\left.\phi_{e}\right)$, the parameters $W_{\gamma}^{\text {curve }}$ and $D^{\text {curve }}$ can be derived by the following expressions:

$$
\begin{aligned}
& W_{\gamma}^{\text {curve }} \\
& \quad=2 \omega \gamma\left[\int _ { \theta _ { 0 } } ^ { \theta _ { \mathrm { B } } } \int _ { 0 } ^ { \sqrt { R ^ { 2 } - a ^ { 2 } } } \int _ { a } ^ { \sqrt { R ^ { 2 } - x ^ { 2 } } } \left(r_{\mathrm{m}}\right.\right. \\
& +y)^{2} \cos \theta \mathrm{d} y \mathrm{~d} x \mathrm{~d} \theta+\int_{\theta_{\mathrm{B}}}^{\theta_{\mathrm{h}}} \int_{0}^{\sqrt{R^{2}-d^{2}}} \int_{d}^{\sqrt{R^{2}-x^{2}}}\left(r_{\mathrm{m}}\right. \\
& \left.+y)^{2} \cos \theta \mathrm{d} y \mathrm{~d} x \mathrm{~d} \theta\right]
\end{aligned}
$$

$$
\begin{aligned}
& D^{\text {curve }} \\
& \quad=\frac{2 c_{\mathrm{e}} \omega r_{0}^{2}}{\tan \phi_{\mathrm{e}}}\left[\left(-\sin ^{2} \theta_{0}\right.\right. \\
& \left.\quad \cdot \int_{\theta_{0}}^{\theta_{\mathrm{B}}} \frac{\cos \theta}{\sin ^{3} \theta} \sqrt{R^{2}-a^{2}} \mathrm{~d} \theta\right)+\left(-\sin ^{2}\left(\beta+\theta_{\mathrm{h}}\right)\right. \\
& \left.\left.\cdot e^{2\left(\theta_{\mathrm{h}}-\theta_{0}\right) \tan \phi_{\mathrm{e}}} \int_{\theta_{\mathrm{B}}}^{\theta_{\mathrm{h}}} \frac{\cos (\theta+\beta)}{\sin ^{3}(\theta+\beta)} \sqrt{R^{2}-d^{2}} \mathrm{~d} \theta\right)\right]
\end{aligned}
$$

For 3D base failure mechanism (Figure 2(b)), an additional angle $\beta^{\prime}$ is considered to determine the slip surface geometry. By applying the equivalent strength parameters $c_{e}$ and $\phi_{e}$, the parameters $W_{\gamma}^{\text {curve }}$ and $D^{\text {curve }}$ can be derived as 


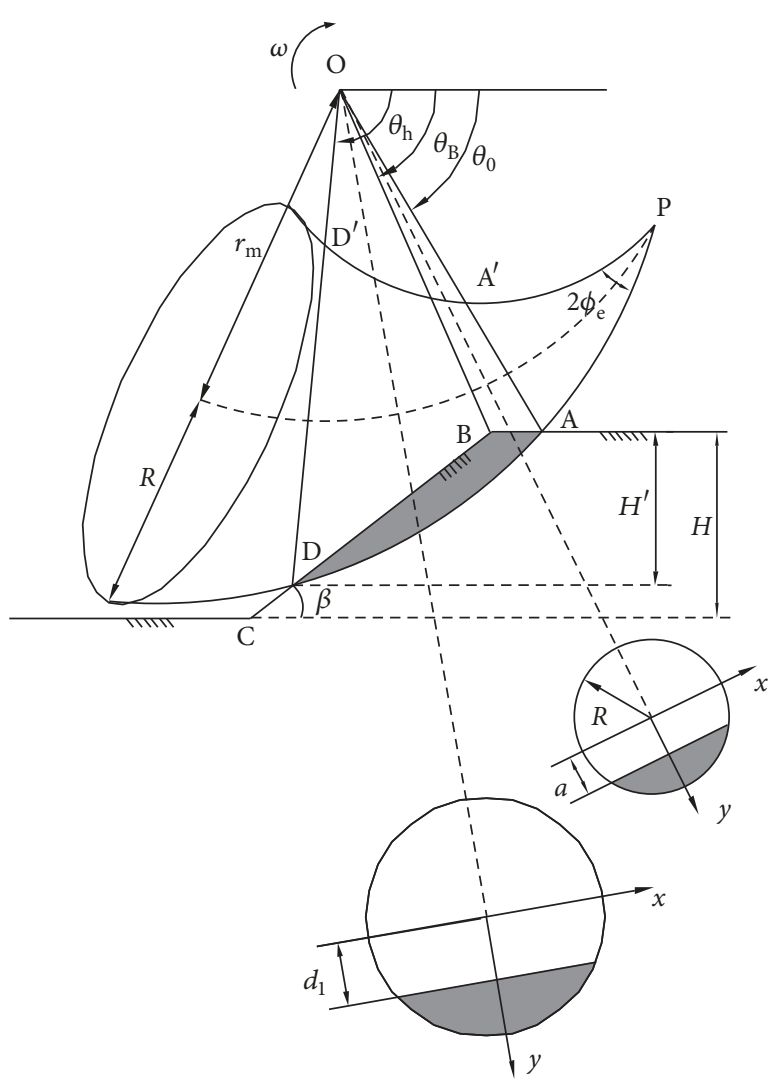

(a)

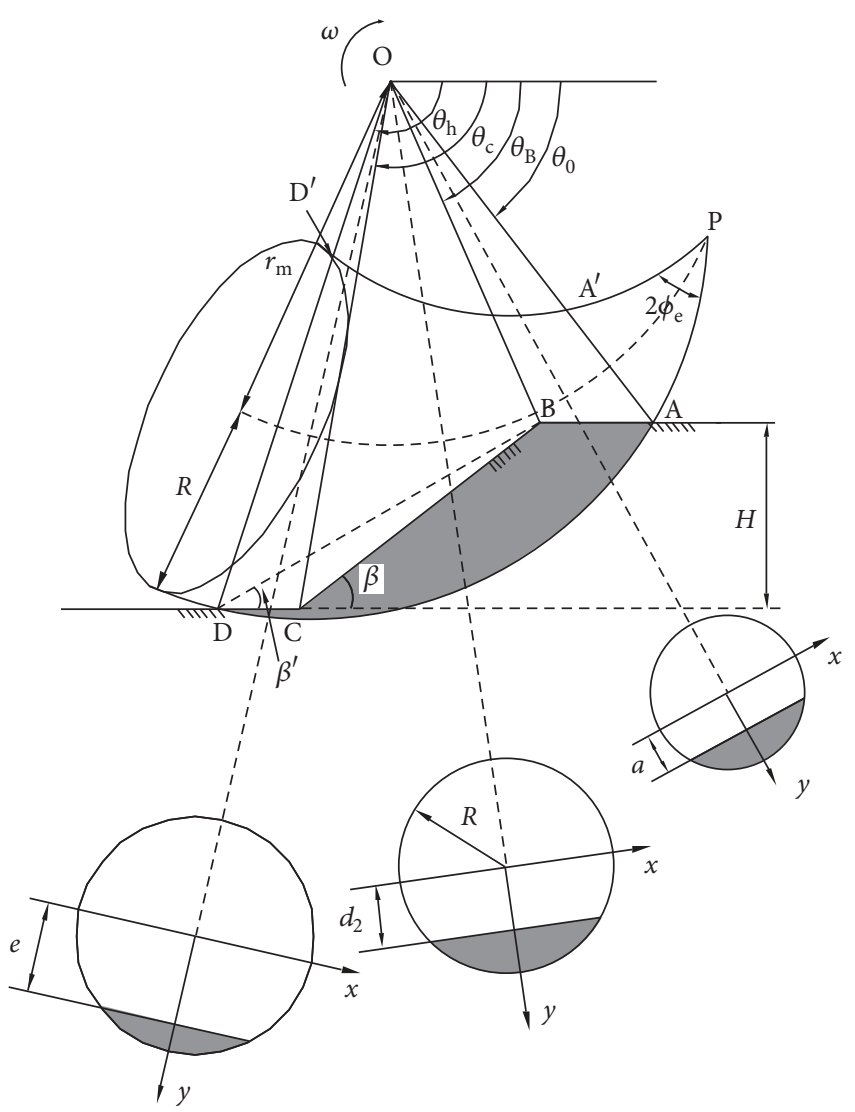

(b)

FIgURE 2: Modified 3D failure mechanisms: (a) face failure mechanism and (b) base failure mechanism [31].

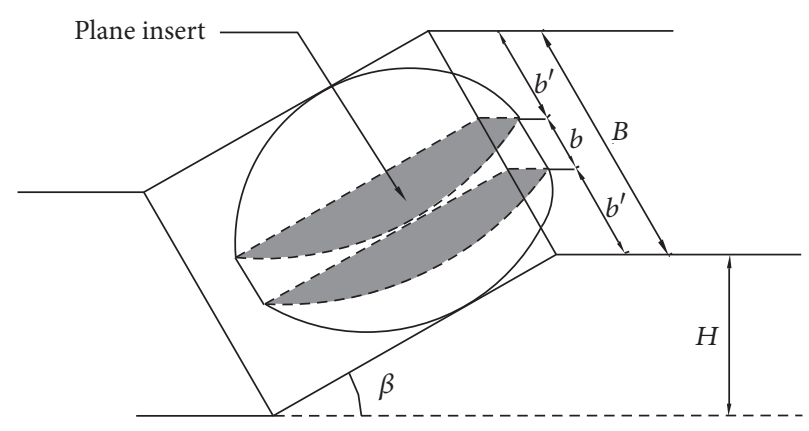

(a)

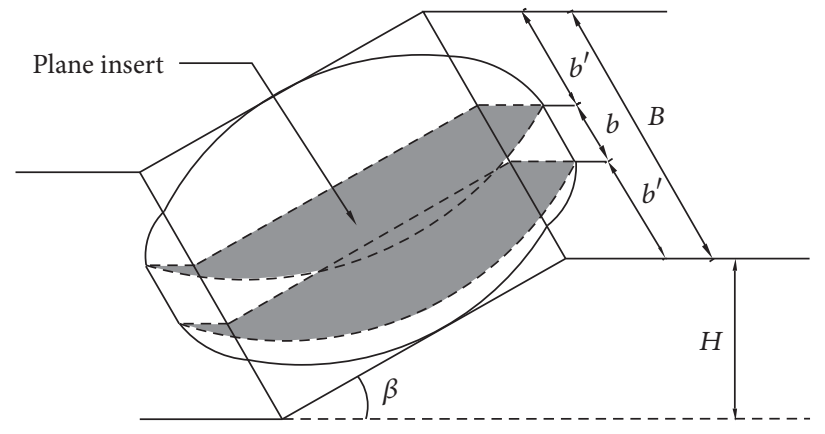

(b)

FIGURE 3: Modified 3D failure mechanisms with the insertosome: (a) face failure mechanism and (b) base failure mechanism [31].

follows:

$$
\begin{gathered}
W_{\gamma}^{\text {curve }}=2 \omega \gamma\left[\int_{\theta_{0}}^{\theta_{\mathrm{B}}} \int_{0}^{\sqrt{R^{2}-a^{2}}} \int_{a}^{\sqrt{R^{2}-x^{2}}}\left(r_{\mathrm{m}}+y\right)^{2} \cos \theta \mathrm{d} y \mathrm{~d} x \mathrm{~d} \theta\right. \\
+\int_{\theta_{\mathrm{B}}}^{\theta_{\mathrm{C}}} \int_{0}^{\sqrt{R^{2}-d^{2}}} \int_{d}^{\sqrt{R^{2}-x^{2}}}\left(r_{\mathrm{m}}+y\right)^{2} \cos \theta \mathrm{d} y \mathrm{~d} x \mathrm{~d} \theta \\
\left.+\int_{\theta_{\mathrm{C}}}^{\theta_{\mathrm{h}}} \int_{0}^{\sqrt{R^{2}-e^{2}}} \int_{e}^{\sqrt{R^{2}-x^{2}}}\left(r_{\mathrm{m}}+y\right)^{2} \cos \theta \mathrm{d} y \mathrm{~d} x \mathrm{~d} \theta\right]
\end{gathered}
$$

$$
\begin{aligned}
& D^{\text {cure }}=\frac{2 c_{\mathrm{e}} \omega r_{0}^{2}}{\tan \phi_{\mathrm{e}}}\left[\left(-\sin ^{2} \theta_{0} \int_{\theta_{0}}^{\theta_{\mathrm{B}}} \frac{\cos \theta}{\sin ^{3} \theta} \sqrt{R^{2}-a^{2}} \mathrm{~d} \theta\right)\right. \\
& \quad+\left(-\frac{\sin ^{2}\left(\beta+\theta_{\mathrm{C}}\right) \sin ^{2} \theta_{\mathrm{h}}}{\sin ^{2} \theta_{\mathrm{C}}} \exp \left[2\left(\theta_{\mathrm{h}}-\theta_{0}\right) \tan \phi_{\mathrm{e}}\right]\right. \\
& \left.\quad \cdot \int_{\theta_{\mathrm{B}}}^{\theta_{\mathrm{C}}} \frac{\cos (\theta+\beta)}{\sin ^{3}(\theta+\beta)} \sqrt{R^{2}-d^{2}} \mathrm{~d} \theta\right) \\
& \left.\quad+\left(-\sin ^{2} \theta_{\mathrm{h}} \exp \left[2\left(\theta_{\mathrm{h}}-\theta_{0}\right) \tan \phi_{\mathrm{e}}\right] \int_{\theta_{\mathrm{C}}}^{\theta_{\mathrm{h}}} \frac{\cos \theta}{\sin ^{3} \theta} \sqrt{R^{2}-e^{2}} \mathrm{~d} \theta\right)\right]
\end{aligned}
$$


where the parameter $c_{\mathrm{e}}$ is the equivalent cohesion, which can be expressed by the function of the equivalent friction angle $\phi_{\mathrm{e}}$ (Equation (6)). The parameters $a, d, e, \theta_{\mathrm{B}}$, and $\theta_{\mathrm{C}}$ are obtained by the following expressions:

$$
\begin{aligned}
a & =\frac{\sin \theta_{0}}{\sin \theta} r_{0}-r_{\mathrm{m}} \\
d & =r_{0} \frac{\sin \left(\theta_{\mathrm{C}}+\beta\right) \sin \theta_{\mathrm{h}}}{\sin (\theta+\beta) \sin \theta_{\mathrm{C}}} \exp \left[\left(\theta_{\mathrm{h}}-\theta_{0}\right) \tan \phi_{\mathrm{e}}\right]-r_{\mathrm{m}} \\
e & =r_{0} \frac{\sin \theta_{\mathrm{h}}}{\sin \theta} \exp \left[\left(\theta_{\mathrm{h}}-\theta_{0}\right) \tan \phi_{\mathrm{e}}\right]-r_{\mathrm{m}} \\
\theta_{\mathrm{B}} & =\arctan \frac{\sin \theta_{0}}{\cos \theta_{0}-A^{\prime}} \\
\theta_{\mathrm{C}} & =\arctan \frac{\sin \theta_{\mathrm{h}} \exp \left[\left(\theta_{\mathrm{h}}-\theta_{0}\right) \tan \phi_{\mathrm{e}}\right]}{\cos \theta_{0}-A^{\prime}-\left\{\sin \theta_{\mathrm{h}} \exp \left[\left(\theta_{\mathrm{h}}-\theta_{0}\right) \tan \phi_{\mathrm{e}}\right]-\sin \theta_{0}\right\} / \tan \beta} \\
A^{\prime} & =\frac{\sin \left(\theta_{\mathrm{h}}-\theta_{0}\right)}{\sin \theta_{\mathrm{h}}}-\frac{\sin \left(\theta_{\mathrm{h}}+\beta\right)}{\sin \theta_{\mathrm{h}} \sin \beta}\left\{\sin \theta_{\mathrm{h}} \exp \left[\left(\theta_{\mathrm{h}}-\theta_{0}\right) \tan \phi_{\mathrm{e}}\right]-\sin \theta_{0}\right\}
\end{aligned}
$$

On the base of the energy-balance equation, the upperbound solutions (i.e., the critical height $H_{\mathrm{cr}}$ ) would be derived for a soil slope with given parameters (i.e., slope inclination angle $\beta$, nonlinear parameters $m, c_{0}, \sigma_{0}$, and relative width $B / H)$. To obtain the least upper bound on the critical height, this study adopted a numerical optimization method presented by Chen [32]. The optimization procedure was performed by using a computer code of Matlab software. The least upper-bound solutions can be calculated with respect to several independent variables: angles $\theta_{0}$ and $\theta_{\mathrm{h}}$, ratio of $r_{0}{ }^{\prime} / r_{0}$, relative width of the plane insert $b / H$, ratio $n=H^{\prime} / H$ for the $3 \mathrm{D}$ face-failure mechanism or angle $\beta^{\prime}$ for the $3 \mathrm{D}$ base-failure mechanism, and one additional variable $\phi_{\mathrm{e}}$. The variables $\theta_{0}$, $\theta_{\mathrm{h}}, r_{0}{ }^{\prime} / r_{0}, b / H, n$, or $\beta^{\prime}$ determine the failure mechanism, and the variable $\phi_{\mathrm{e}}$ determines the location of tangent line of PL strength criterion. More details for the interpretations and notations of 3D limit analysis method can be found in the references of Michalowski \& Drescher [30] and Gao et al. [31].

2.3. Determination of Approximate MC Parameters. As presented in the $3 \mathrm{D}$ limit analysis method, the equivalent friction angle $\phi_{\mathrm{e}}$ represents the apex angle of the curvilinear cone. Hence, the parameter $\phi_{\mathrm{e}}$ is a significant variable in the energy-balance equation. The variable $\phi_{\mathrm{e}}$ can be obtained once the least upper-bound solutions are determined in the optimization procedure. Correspondingly, the equivalent cohesion $c_{\mathrm{e}}$ then can be derived with respect to the equivalent friction angle $\phi_{e}$, as illustrated in (6). Since the shear strengths of tangent line are equal to or larger than those of the PL strength envelop in the same normal stress range, the calculated solution will be an upper bound of the actual limit load. Here, the equivalent MC strength parameters (the equivalent friction angle $\phi_{\mathrm{e}}$ and the equivalent cohesion $c_{\mathrm{e}}$ ) are not the conventional strength parameters to reflect the soil nature. But, they can represent the approximate shear strengths of the relevant stress distribution acting on the slope critical slip surface. Therefore, the obtained values of $\phi_{e}$ and $c_{\mathrm{e}}$ can be used as the approximate MC strength parameters in slope engineering.

\section{Numerical Results and Analyses}

3.1. Effect of $\mathcal{c}_{0} / \sigma_{0}$ on Equivalent $M C$ Parameters. Selecting two $3 \mathrm{D}$ slopes $(B / H=2.0)$ with $\beta=30^{\circ}$ and $\beta=60^{\circ}$ as examples, Figures 4 and 5 present the equivalent $\mathrm{MC}$ strength parameters (the equivalent friction angle $\phi_{e}$ and the equivalent cohesion $c_{\mathrm{e}} / c_{0}$ ) as the $\mathrm{X}$-coordinate is the strength parameter ratio of $c_{0} / \sigma_{0}$. Considering different nonlinearity coefficients $m$ (1.2, 1.6 and 2.0), three changing lines were presented in each figure. It should be noted that the strength parameter ratio of $c_{0} / \sigma_{0}$ is adopted as dimensionless parameter, which is consistent with the equivalent cohesion $c_{\mathrm{e}} / c_{0}$.

For gentle slopes with $\beta=30^{\circ}$ (Figure 4 ), the equivalent friction angle $\phi_{\mathrm{e}}$ appears to be bigger as the ratio of $c_{0} / \sigma_{0}$ increases. However, the increasing trend becomes weaker when the ratio of $c_{0} / \sigma_{0}$ is relatively bigger. From Figure 4(a), it can be seen that the changing lines tend to be horizontal in the big range of $c_{0} / \sigma_{0}$. Correspondingly, the equivalent cohesion $c_{\mathrm{e}} / c_{0}$ becomes larger gradually as the ratio of $c_{0} / \sigma_{0}$ increases. By comparing the changing lines with respect to different parameters $m$, it can be found that the influences of the ratio of $c_{0} / \sigma_{0}$ on the equivalent MC parameters become more remarkable with the decreasing value of $m$.

Nevertheless, for steep slopes (Figure 5), the equivalent friction angle $\phi_{\mathrm{e}}$ and the equivalent cohesion $c_{\mathrm{e}} / c_{0}$ become bigger gradually with the increasing $c_{0} / \sigma_{0}$. Meanwhile, as the strength parameter $m$ decreases, the effect of the ratio of $c_{0} / \sigma_{0}$ on the equivalent friction angle $\phi_{\mathrm{e}}$ was found to be more significant. But the effect of $c_{0} / \sigma_{0}$ on the equivalent cohesion $c_{\mathrm{e}} / c_{0}$ appears to be slight. 


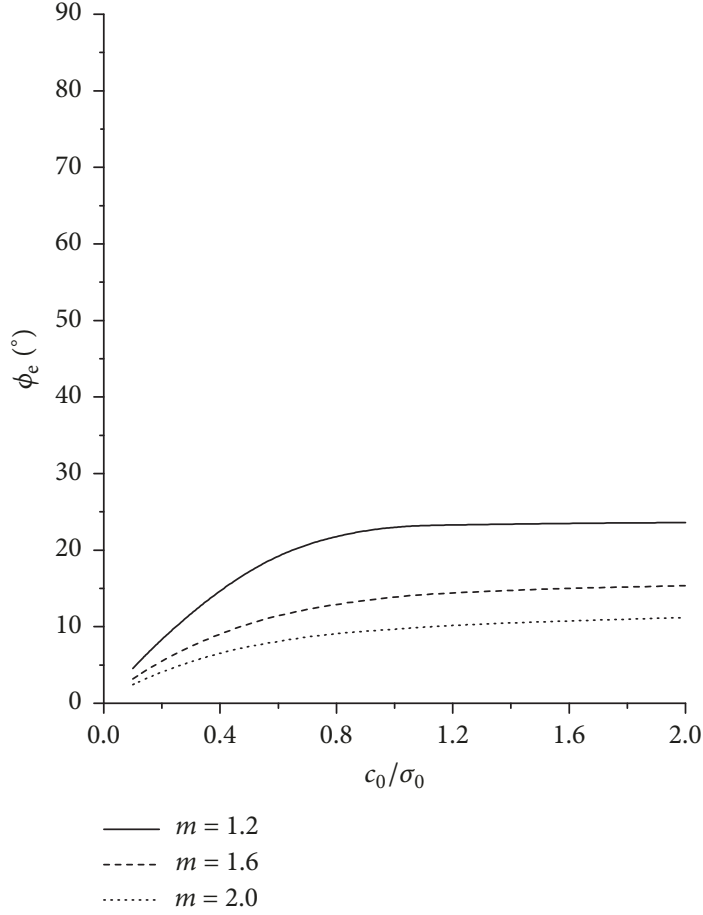

(a)

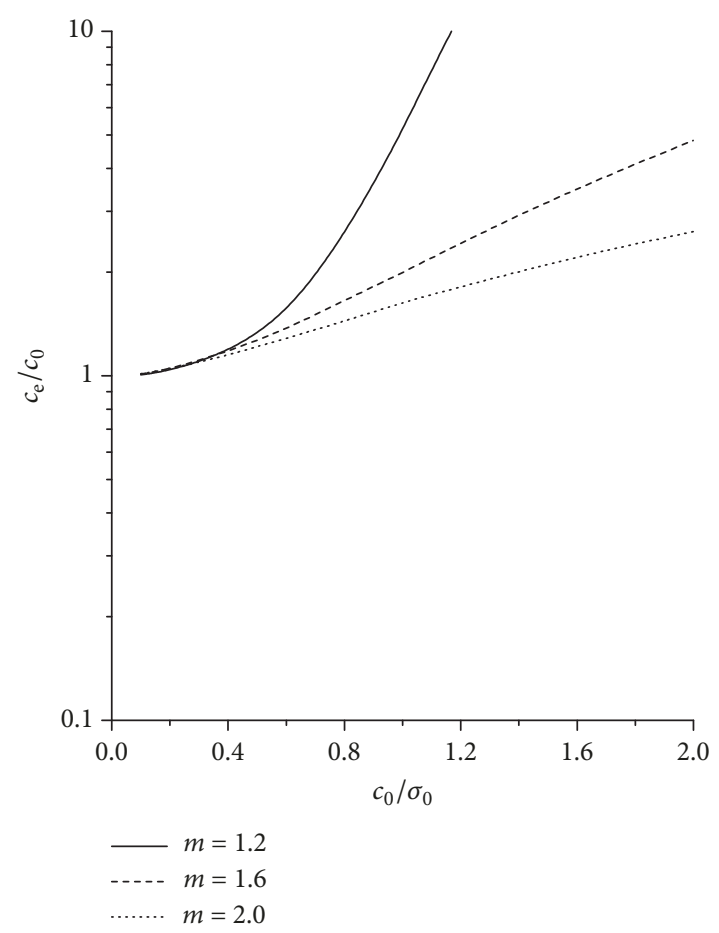

(b)

FIGURE 4: Effect of $c_{0} / \sigma_{0}$ on equivalent MC parameters $\left(\beta=30^{\circ}\right)$.

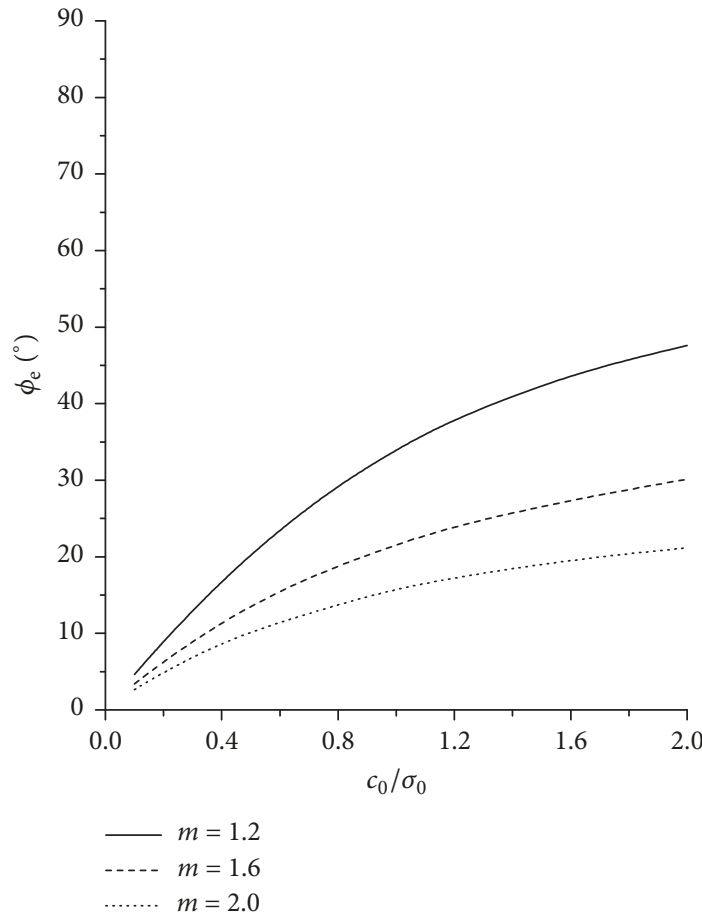

(a)

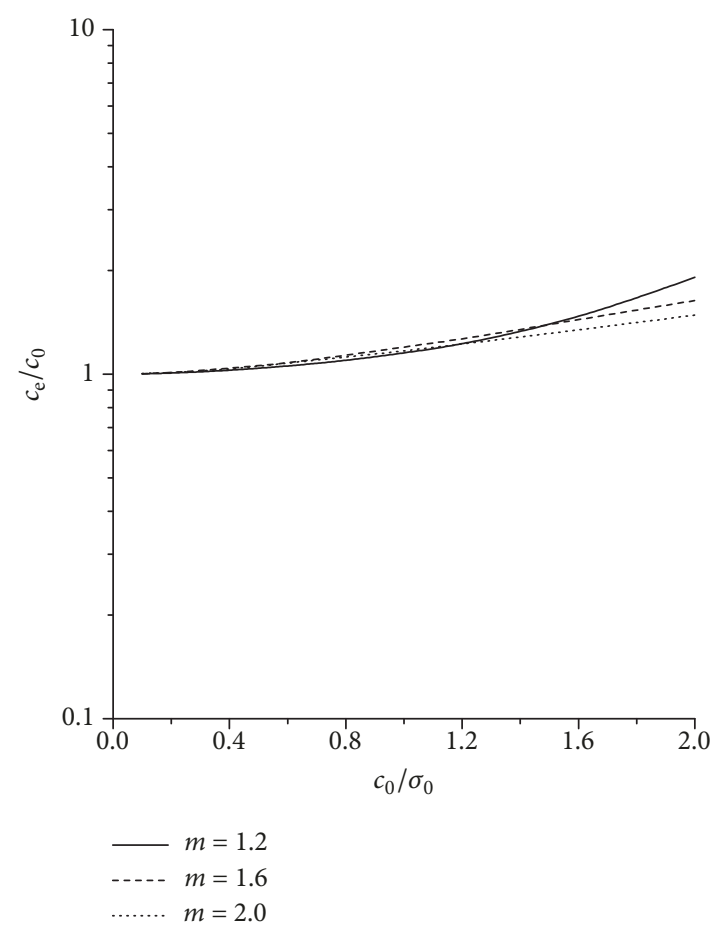

(b)

Figure 5: Effect of $c_{0} / \sigma_{0}$ on equivalent MC parameters $\left(\beta=60^{\circ}\right)$. 


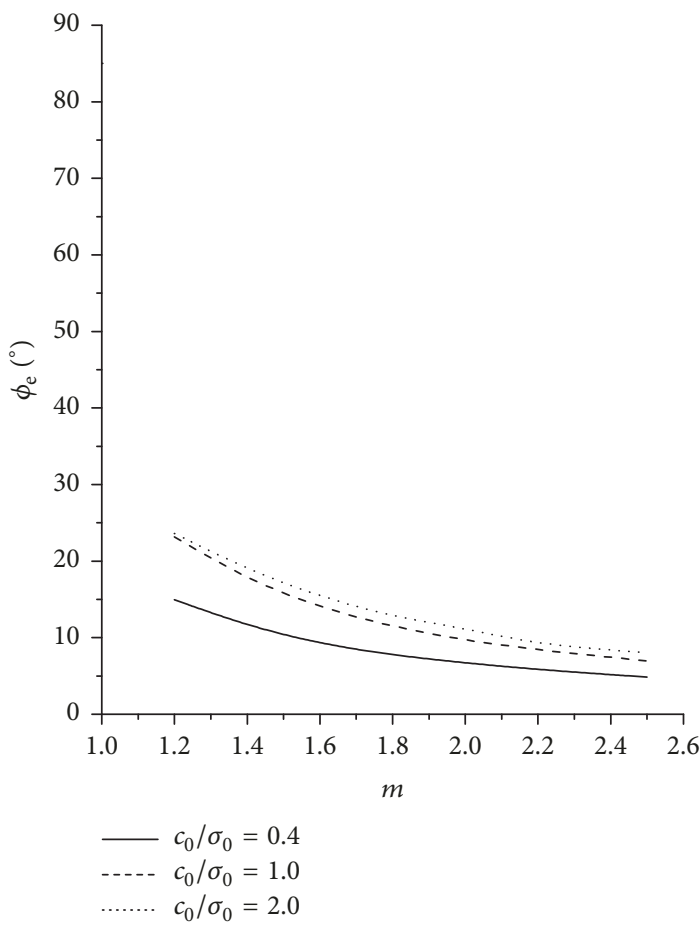

(a)

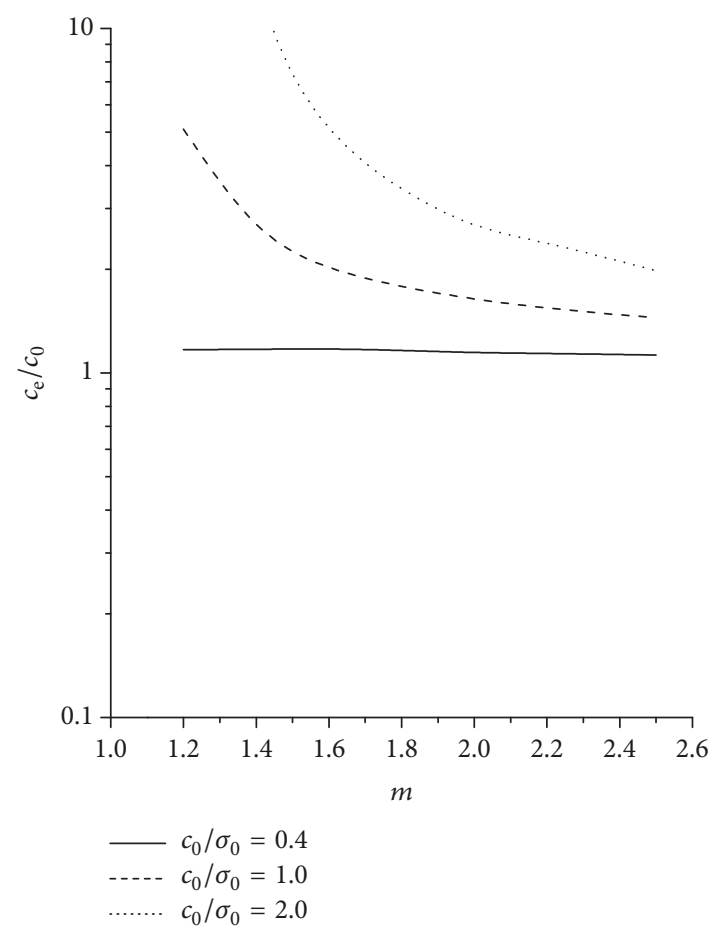

(b)

FIGURE 6: Effect of $m$ on equivalent MC parameters $\left(\beta=30^{\circ}\right)$.

3.2. Effect of $m$ on Equivalent MC Parameters. Figures 6 and 7 illustrate the influences of the nonlinearity coefficient $m$ on the equivalent MC strength parameters $\left(\phi_{\mathrm{e}}\right.$ and $\left.c_{\mathrm{e}} / c_{0}\right)$ for $3 \mathrm{D}$ slopes with $\beta=30^{\circ}$ and $\beta=60^{\circ}$. Here, the relative width for each slope was assumed as $B / H=2.0$. From Figures 6 and 7 , it can be found that the equivalent friction angle $\phi_{\mathrm{e}}$ and the equivalent cohesion $c_{\mathrm{e}} / c_{0}$ both become smaller as the parameter $m$ increases, whether for gentle slopes or steep slopes. The influences of the parameter $m$ on the equivalent strength parameters tend to be less pronounced with the decreasing ratio of $c_{0} / \sigma_{0}$, especially for steep slopes with the small ratio of $c_{0} / \sigma_{0}$. As illustrated in Figure 7(b), for slopes with $\beta=60^{\circ}$ and $c_{0} / \sigma_{0}=2.0$, the equivalent cohesion $c_{\mathrm{e}} / c_{0}$ would change slightly as the parameter $m$ increases.

3.3. Effect of $\beta$ on Equivalent MC Parameters. To explore the effects of the slope angle $\beta$ on the equivalent MC strength parameters $\left(\phi_{\mathrm{e}}\right.$ and $\left.c_{\mathrm{e}} / \mathcal{c}_{0}\right)$, Figures $8(\mathrm{a})$ and $8(\mathrm{~b})$ present the different values of $\phi_{\mathrm{e}}$ and $c_{\mathrm{e}} / c_{0}$ by taking the inclination angle $\beta$ as the $\mathrm{x}$-coordinate. Four kinds of conditions were considered in this section: $c_{0} / \sigma_{0}=0.4, m=1.2 ; c_{0} / \sigma_{0}=$ $0.4, m=2.0 ; c_{0} / \sigma_{0}=2.0 m=1.2 ; c_{0} / \sigma_{0}=2.0, m=2.0$. In each condition, the slope relative width $B / H=2.0$ was adopted.

It is obvious that the equivalent friction angle $\phi_{\mathrm{e}}$ becomes larger as the inclination angle $\beta$ increases. However, the equivalent cohesion $c_{\mathrm{e}} / c_{0}$ becomes smaller with the increasing angle $\beta$. Comparing these four conditions of $c_{0} / \sigma_{0}$ and $m$, the influences of angle $\beta$ on the equivalent MC parameters appear to be more significant for soil slopes with the larger $c_{0} / \sigma_{0}$ and the smaller $m$.

3.4. Effect of $\mathrm{B} / \mathrm{H}$ on Equivalent $\mathrm{MC}$ Parameters. Figure 9 gives the values of the equivalent friction angle $\phi_{\mathrm{e}}$ for two slopes $\left(\beta=30^{\circ}\right.$ and $\left.\beta=60^{\circ}\right)$ with respect to different relative widths $B / H$. Similarly, four kinds of combinations of $c_{0} / \sigma_{0}$ and $m$ were presented in these figures. For gentle and steep slopes (Figures 9(a) and 9(b)), the equivalent friction angle $\phi_{\mathrm{e}}$ was found to be almost constant as the ratio of $\mathrm{B} / \mathrm{H}$ increases. Since the equivalent cohesion $c_{\mathrm{e}} / c_{0}$ is a function of the equivalent friction angle $\phi_{\mathrm{e}}$ (as presented in Equation (6)), the equivalent cohesion $c_{\mathrm{e}} / c_{0}$ would also change slightly with the increasing $B / H$. The phenomenon may reveal that $3 \mathrm{D}$ effects nearly have no influences on equivalent MC strength parameters, although $3 \mathrm{D}$ effects have significant influences on the slope stability $[14,15]$.

3.5. Charts of Approximate MC Parameters. Based on the above results and analyses, it can be concluded that the nonlinear strength parameters and the slope inclination have significant influences on the equivalent MC parameters $\left(\phi_{\mathrm{e}}\right.$ and $\left.c_{\mathrm{e}} / c_{0}\right)$. Nevertheless, 3D effects on the equivalent $\mathrm{MC}$ parameters can be ignored (but 3D effects on the slope stability are significant). Hence, this study derived the equivalent MC parameters with respect to various nonlinear strength parameters and common slope inclinations for 2D soil slopes, as presented in Tables 1 and 2. The approximate MC strength parameters in these charts can be alternative references in the 


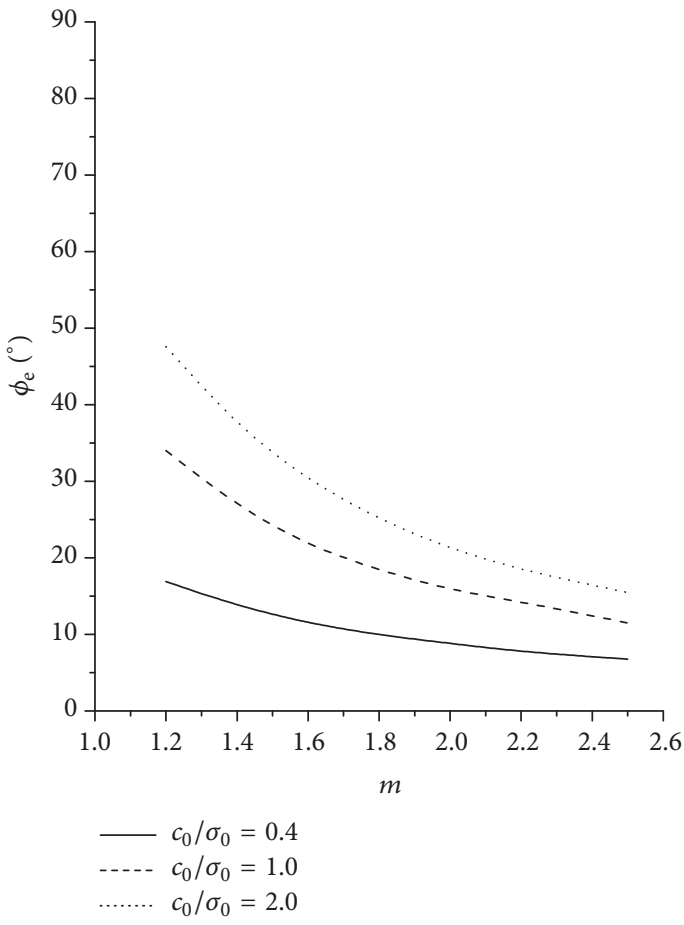

(a)

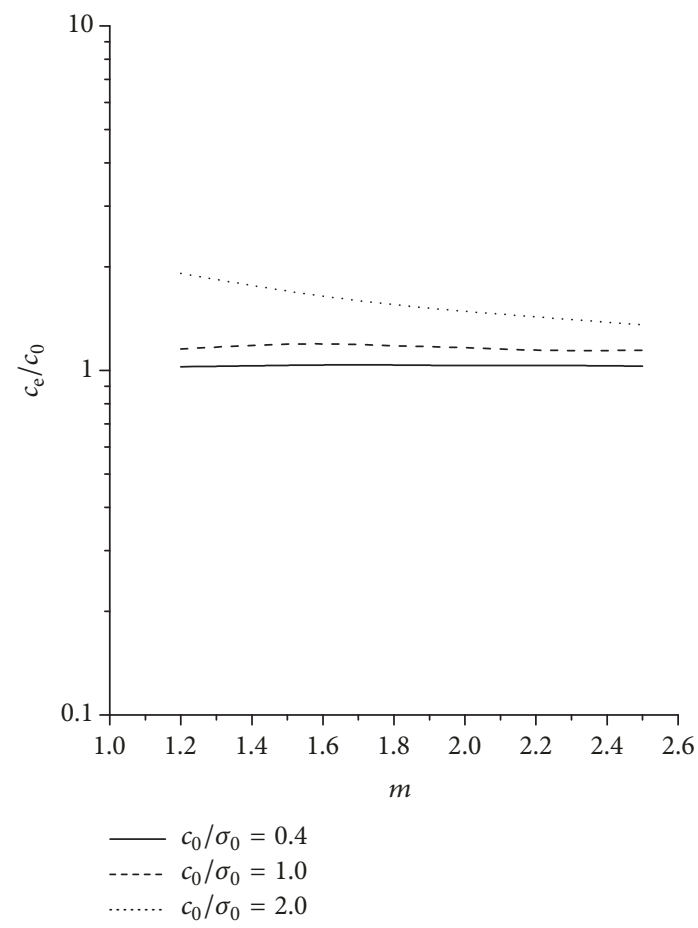

(b)

FIGURE 7: Effect of $m$ on equivalent MC parameters $\left(\beta=60^{\circ}\right)$.

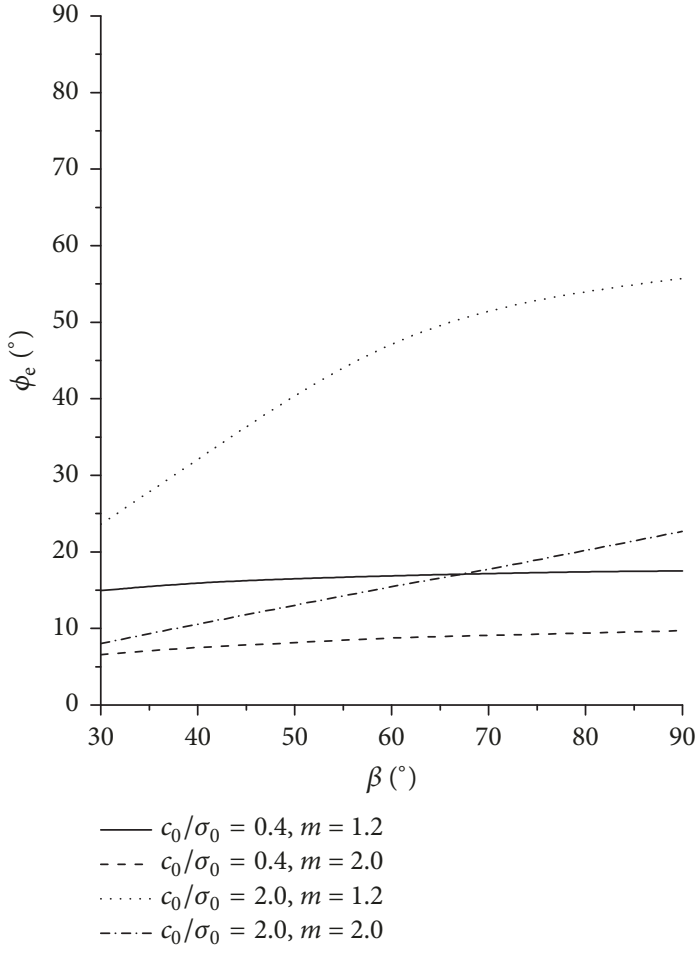

(a)

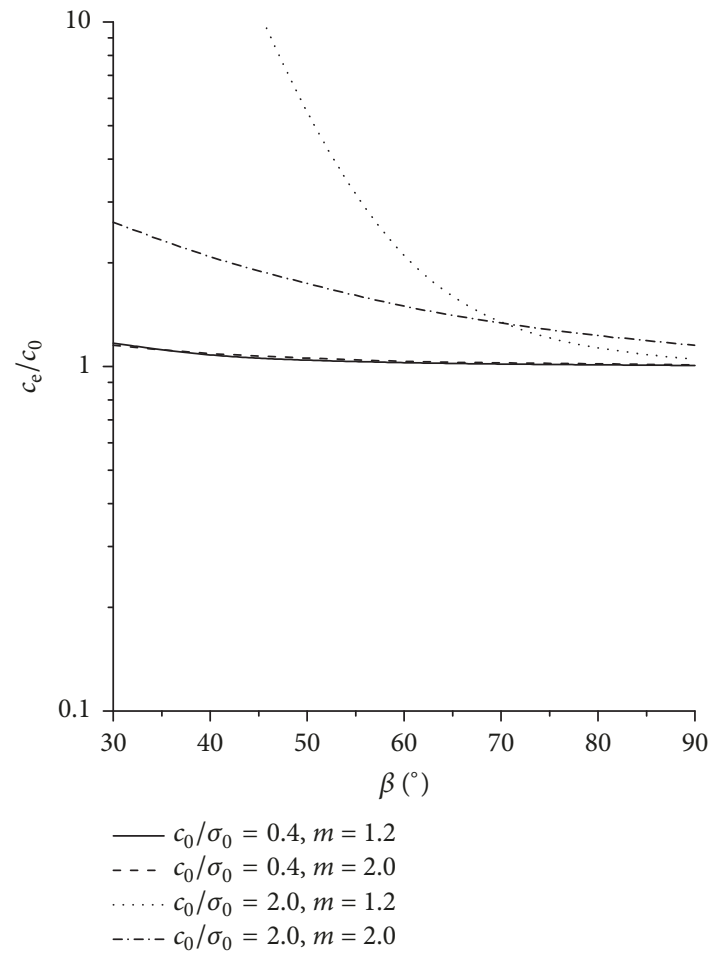

(b)

Figure 8: Effect of $\beta$ on equivalent MC parameters. 


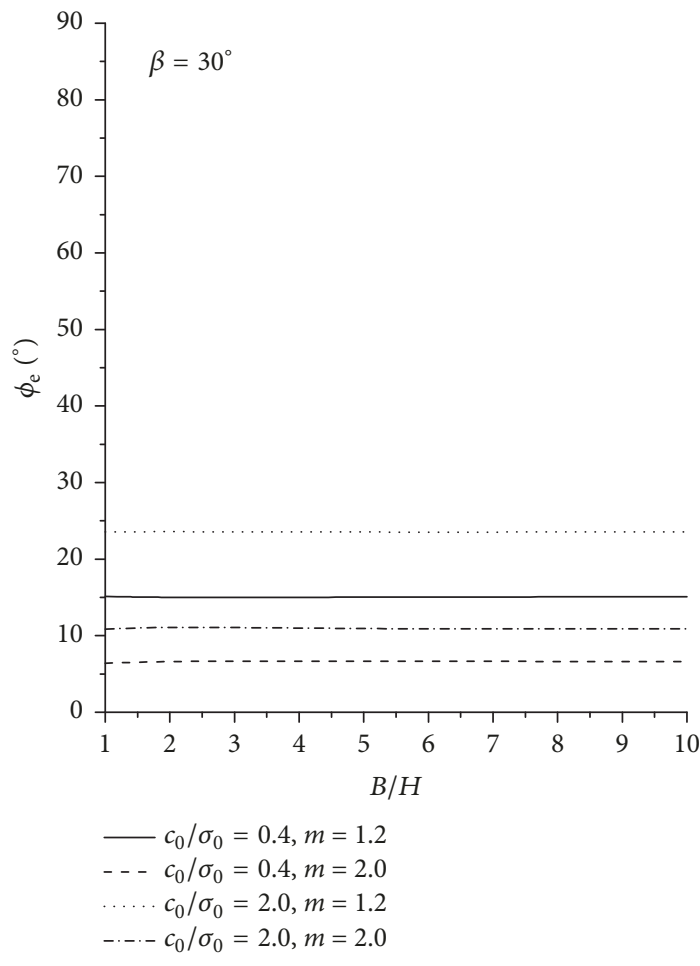

(a)

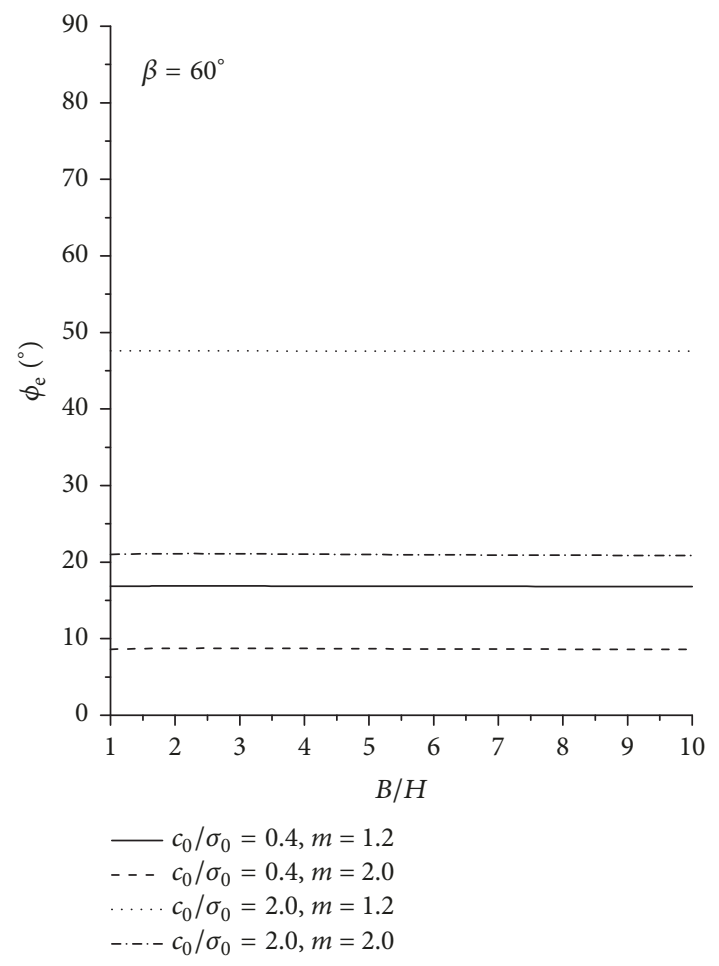

(b)

Figure 9: Effect of $B / H$ on equivalent MC parameters: (a) $\beta=30^{\circ}$; (b) $\beta=60^{\circ}$.

software codes and engineering standards for slope design practice.

\section{Example Problems}

To verify the accuracy of the presented method and the applicability of the given approximate MC parameters, this section provides two examples of uniform dry soil slopes in plain-strain conditions. Since the limit analysis method focuses on the critical state of slope failure, the safety factors for slopes are assumed as $F=1.0$ in the above studies, and the critical height $H_{\mathrm{cr}}$ are used as the upper-bound solutions for slope stability. For comparisons with the other results represented by $F$, the shear strength can be reduced by the safety factor $F$ and the minimum safety factors will be derived by using the presented limit analysis method.

4.1. Example 1. For the slope in example 1, the geometry parameters are given as $H=12 \mathrm{~m}$ and $\beta=28.2^{\circ}$. This example was utilized by Eid [33] based on the test results of shear strengths given by Chandler [34] for Upper Lias clay. The nonlinear PL strength function can be obtained by curve fitting to the test data using the Levenberg-Marquardt method. The nonlinear strength parameters have the following values: $c_{0}=0.98 \mathrm{kPa}, \sigma_{0}=0.33 \mathrm{kPa}$, and $m=1.38$. The total unit weight $\gamma$ is adopted as $20 \mathrm{kN} / \mathrm{m}^{3}$.

Based on the presented method for this slope with nonlinear parameters, the minimum safety factor is calculated as 1.64. This slope problem has been analyzed by Eid [33] using the limit equilibrium method and another nonlinear failure criterion. He obtained the safety factor of 1.50 , which is a little smaller than the result $(F=1.64)$ of this study. Since the limit analysis method adopted in this study derived the upper-bound solutions for slope stability, the difference of 1.64 versus 1.50 between the safety factors is reasonable and this comparison can confirm the correctness of the presented results in this study.

For slope design, the approximate MC parameters for this slope example can be obtained from Tables 1 and 2 . Given values of $m \approx 1.4, c_{0} / \sigma_{0} \approx 3.0$, and $\beta=28.2^{\circ}$, we can get the equivalent friction angle $\phi_{\mathrm{e}} \approx 17.73^{\circ}$ and the equivalent cohesive $c_{\mathrm{e}} / c_{0} \approx 38.37$ by the interpolation calculations of given values. Using $c_{0}=0.98 \mathrm{kPa}$, the approximate cohesive $c_{\mathrm{e}}$ is determined as $37.60 \mathrm{kPa}$. In condition of the safety factor $F=1.0$, the presented limit analysis method can derive the critical height for this slope, i.e., $H_{\mathrm{cr}}=66.4 \mathrm{~m}$. It reveals that the design height for this slope should be smaller than $66.4 \mathrm{~m}$ to ensure its safety.

4.2. Example 2. The problem considered in this example adopts the test data reported by Baker [35] for compacted Israeli clay. The nonlinear strength parameters were derived as follows: $c_{0}=0.06 \mathrm{kPa}, \sigma_{0}=0.02 \mathrm{kPa}$, and $m=1.23$. The slope height $H$ is $6 \mathrm{~m}$ and the slope inclination $\beta$ is $43^{\circ}$. The total unit weight for Israeli clay is taken as $\gamma=18 \mathrm{kN} / \mathrm{m}^{3}$.

For such a problem, the limit analysis method presented in this study yielded the safety factor of 1.14, which is a little larger than the result of $F=0.97$ derived from the 
TABLE 1: The equivalent friction angle $\phi_{\mathrm{e}}\left({ }^{\circ}\right)$ for various soils.

\begin{tabular}{|c|c|c|c|c|c|c|c|c|}
\hline \multirow{2}{*}{$c_{0} / \sigma_{0}$} & \multirow{2}{*}{$\beta\left(^{\circ}\right)$} & \multicolumn{7}{|c|}{$\mathrm{m}$} \\
\hline & & 1.2 & 1.4 & 1.6 & 1.8 & 2.0 & 2.2 & 2.5 \\
\hline \multirow{5}{*}{0.5} & 20 & 14.30 & 10.57 & 8.31 & 6.78 & 5.69 & 4.87 & 3.98 \\
\hline & 30 & 17.52 & 13.15 & 10.50 & 8.72 & 7.44 & 6.49 & 5.43 \\
\hline & 40 & 18.96 & 14.63 & 11.86 & 9.95 & 8.56 & 7.50 & 6.32 \\
\hline & 50 & 19.78 & 15.60 & 12.82 & 10.85 & 9.39 & 8.27 & 7.01 \\
\hline & 60 & 20.33 & 16.30 & 13.53 & 11.54 & 10.05 & 8.89 & 7.57 \\
\hline \multirow{5}{*}{1.0} & 20 & 15.41 & 12.07 & 9.76 & 8.03 & 6.75 & 5.79 & 4.72 \\
\hline & 30 & 22.99 & 17.44 & 13.84 & 11.40 & 9.66 & 8.37 & 6.95 \\
\hline & 40 & 28.73 & 21.55 & 17.08 & 14.08 & 11.95 & 10.36 & 8.62 \\
\hline & 50 & 32.06 & 24.49 & 19.61 & 16.27 & 13.86 & 12.05 & 10.06 \\
\hline & 60 & 34.01 & 26.63 & 21.61 & 18.07 & 15.48 & 13.52 & 11.34 \\
\hline \multirow{5}{*}{2.0} & 20 & 15.45 & 12.35 & 10.13 & 8.47 & 7.19 & 6.19 & 5.08 \\
\hline & 30 & 23.54 & 18.77 & 15.28 & 12.74 & 10.86 & 9.43 & 7.85 \\
\hline & 40 & 32.06 & 25.32 & 20.36 & 16.85 & 14.29 & 12.37 & 10.26 \\
\hline & 50 & 40.63 & 31.64 & 25.26 & 20.81 & 17.60 & 15.21 & 12.59 \\
\hline & 60 & 47.52 & 37.19 & 29.79 & 24.56 & 20.78 & 17.96 & 14.87 \\
\hline \multirow{5}{*}{3.0} & 20 & 15.46 & 12.38 & 10.20 & 8.55 & 7.28 & 6.29 & 5.17 \\
\hline & 30 & 23.55 & 18.91 & 15.52 & 13.03 & 11.17 & 9.73 & 8.12 \\
\hline & 40 & 32.17 & 25.88 & 21.11 & 17.61 & 15.00 & 13.02 & 10.82 \\
\hline & 50 & 41.45 & 33.36 & 27.00 & 22.36 & 18.95 & 16.38 & 13.57 \\
\hline & 60 & 51.13 & 41.09 & 33.12 & 27.30 & 23.05 & 19.87 & 16.40 \\
\hline \multirow{5}{*}{5.0} & 20 & 15.46 & 12.40 & 10.23 & 8.59 & 7.33 & 6.35 & 5.23 \\
\hline & 30 & 23.55 & 18.94 & 15.62 & 13.18 & 11.34 & 9.91 & 8.30 \\
\hline & 40 & 32.18 & 26.05 & 21.45 & 18.02 & 15.43 & 13.44 & 11.21 \\
\hline & 50 & 41.54 & 33.97 & 27.90 & 23.30 & 19.85 & 17.22 & 14.30 \\
\hline & 60 & 51.86 & 43.03 & 35.25 & 29.25 & 24.77 & 21.38 & 17.66 \\
\hline
\end{tabular}

limit equilibrium method of Baker [35]. The small difference can verify the accuracy of the solutions derived from the presented method. Besides, considering the values of $m=$ $1.23, c_{0} / \sigma_{0}=0.06 / 0.02=3.0$, and $\beta=43^{\circ}$, the approximate MC parameters $\phi_{\mathrm{e}} \approx 33.93^{\circ}$ and $c_{\mathrm{e}} \approx 3.19 \mathrm{kPa}$ are determined from Tables 1 and 2 . Hence, the critical height for this slope can be calculated as $H_{\mathrm{cr}}=12.9 \mathrm{~m}$ by using the presented limit analysis method with $F=1.0$.

\section{Conclusions}

On the base of 3D failure mechanisms for soil slopes with the MC strength criterion, this paper employed the tangential method to develop the upper-bound limit analysis of slope stability with the nonlinear PL strength criterion. A numerical optimization procedure written in a computer code of Matlab software was applied to calculate the upper-bound solutions of slope stability. The equivalent MC strength parameters from the PL strength envelope were then derived with respect to the least upper-bound solutions. Effects of nonlinear strength parameters and slope geometries on the equivalent MC parameters have been well studied, and design chats of approximate MC strength parameters have been provided for various soil slopes. From this study, the main conclusions can be made as follows:
(1) The equivalent MC strength parameters $\phi_{\mathrm{e}}$ and $c_{\mathrm{e}} / c_{0}$ both tend to be larger gradually with the increasing ratio of $c_{0} / \sigma_{0}$. However, the effects of the nonlinearity coefficient $m$ on the equivalent MC strength parameters are opposite; namely, the equivalent friction angle $\phi_{\mathrm{e}}$ and the equivalent cohesion $c_{\mathrm{e}} / \mathcal{c}_{0}$ become smaller with the increasing $m$.

(2) As the inclination angle $\beta$ increases, the equivalent friction angle $\phi_{\mathrm{e}}$ becomes bigger and the equivalent cohesion $c_{\mathrm{e}} / c_{0}$ becomes smaller. The influences of the inclination on the equivalent MC parameters seem to be more pronounced for soil slopes with the bigger value of $c_{0} / \sigma_{0}$ or smaller value of $m$.

(3) Although $3 \mathrm{D}$ effect has significant influences on the safety of soil slopes, 3D effect on the equivalent MC strength parameters seems to be slight.

\section{Data Availability}

The data used to support the findings of this study are available from the corresponding author upon request.

\section{Conflicts of Interest}

The authors declare that they have no conflicts of interest. 
TABLE 2: The equivalent cohesive $c_{\mathrm{e}} / c_{0}$ for various soils.

\begin{tabular}{|c|c|c|c|c|c|c|c|c|}
\hline \multirow{2}{*}{$c_{0} / \sigma_{0}$} & \multirow{2}{*}{$\beta\left(^{\circ}\right)$} & \multicolumn{7}{|c|}{$\mathrm{m}$} \\
\hline & & 1.2 & 1.4 & 1.6 & 1.8 & 2.0 & 2.2 & 2.5 \\
\hline \multirow{5}{*}{0.5} & 20 & 2.46 & 1.82 & 1.62 & 1.52 & 1.45 & 1.41 & 1.35 \\
\hline & 30 & 1.30 & 1.29 & 1.27 & 1.24 & 1.22 & 1.20 & 1.18 \\
\hline & 40 & 1.12 & 1.15 & 1.15 & 1.14 & 1.13 & 1.12 & 1.11 \\
\hline & 50 & 1.07 & 1.09 & 1.09 & 1.09 & 1.09 & 1.08 & 1.08 \\
\hline & 60 & 1.04 & 1.06 & 1.06 & 1.06 & 1.06 & 1.06 & 1.05 \\
\hline \multirow{5}{*}{1.0} & 20 & 42.32 & 6.05 & 3.39 & 2.61 & 2.23 & 2.01 & 1.80 \\
\hline & 30 & 5.30 & 2.54 & 2.02 & 1.78 & 1.64 & 1.54 & 1.45 \\
\hline & 40 & 1.90 & 1.65 & 1.53 & 1.45 & 1.39 & 1.35 & 1.30 \\
\hline & 50 & 1.32 & 1.34 & 1.31 & 1.29 & 1.26 & 1.24 & 1.21 \\
\hline & 60 & 1.15 & 1.19 & 1.20 & 1.19 & 1.18 & 1.17 & 1.15 \\
\hline \multirow{5}{*}{2.0} & 20 & 1329.29 & 31.19 & 9.68 & 5.55 & 4.03 & 3.26 & 2.64 \\
\hline & 30 & 136.66 & 10.52 & 4.87 & 3.37 & 2.70 & 2.33 & 2.01 \\
\hline & 40 & 22.55 & 4.76 & 3.02 & 2.41 & 2.09 & 1.89 & 1.71 \\
\hline & 50 & 5.04 & 2.65 & 2.14 & 1.89 & 1.73 & 1.63 & 1.52 \\
\hline & 60 & 1.93 & 1.77 & 1.66 & 1.58 & 1.51 & 1.45 & 1.38 \\
\hline \multirow{5}{*}{3.0} & 20 & 10061.7 & 85.18 & 18.72 & 9.03 & 5.91 & 4.47 & 3.39 \\
\hline & 30 & 1033.92 & 28.09 & 9.13 & 5.32 & 3.87 & 3.13 & 2.53 \\
\hline & 40 & 165.56 & 11.87 & 5.35 & 3.64 & 2.89 & 2.47 & 2.11 \\
\hline & 50 & 30.59 & 5.68 & 3.46 & 2.69 & 2.30 & 2.06 & 1.83 \\
\hline & 60 & 5.95 & 3.00 & 2.40 & 2.10 & 1.90 & 1.77 & 1.63 \\
\hline \multirow{5}{*}{5.0} & 20 & 129396 & 304.20 & 43.49 & 16.95 & 9.74 & 6.76 & 4.71 \\
\hline & 30 & 13296.2 & 99.87 & 21.00 & 9.83 & 6.27 & 4.66 & 3.47 \\
\hline & 40 & 2123.08 & 41.33 & 11.97 & 6.56 & 4.58 & 3.61 & 2.84 \\
\hline & 50 & 383.73 & 18.62 & 7.34 & 4.65 & 3.53 & 2.93 & 2.42 \\
\hline & 60 & 62.77 & 8.37 & 4.61 & 3.40 & 2.80 & 2.44 & 2.11 \\
\hline
\end{tabular}

\section{Acknowledgments}

This study was financially supported by National Natural Science Foundation of China (Grant Nos. 51708310 and 51809160), Shandong Provincial Natural Science Foundation, China (Grant Nos. ZR2017BEE066 and ZR201702160366), a Project of Shandong Province Higher Educational Science and Technology Program (Grant No. J17KB049), and Scientific Research Foundation of Shandong University of Science and Technology for Recruited Talents (Grant No. 2017RCJJ004).

\section{References}

[1] A. W. Bishop, D. L. Webb, and P. I. Lewin, "Undisturbed samples of london clay from the ashford common shaft: Strengtheffective stress relationships," Géotechnique, vol. 15, no. 1, pp. 131, 1965.

[2] V. M. Ponce and J. M. Bell, "Shear strength of sand at extremely low pressures," Journal of the Soil Mechanics Foundations Division, vol. 97, no. 4, pp. 625-638, 1971.

[3] N. Barton and V. Choubey, "The shear strength of rock joints in theory and practice," Rock Mechanics. Felsmechanik Mécanique des Roches, vol. 10, no. 1-2, pp. 1-54, 1977.
[4] E. Hoek and E. T. Brown, "Empirical strength criterion for rock masses," Journal of Geotechnical and Geoenvironmental Engineering, vol. 106, no. GT9, pp. 1013-1035, 1980.

[5] G. Lefebvre, "Strength and slope stability in Canadian soft clay deposits," Canadian Geotechnical Journal, vol. 3, no. 2, pp. 420442, 1981.

[6] R. Ucar, "Determination of shear failure envelope in rock masses," Journal of Geotechnical Engineering, vol. 112, no. 3, pp. 303-315, 1986.

[7] R. Baker, "Nonlinear Mohr envelopes based on triaxial data," Journal of Geotechnical and Geoenvironmental Engineering, vol. 130, no. 5, pp. 498-506, 2004.

[8] J. A. Charles and M. M. Soares, "The stability of slopes in soils with nonlinear failure envelopes," Canadian Geotechnical Journal, vol. 21, no. 3, pp. 397-406, 1984.

[9] X. J. Zhang and W. F. Chen, "Stability analysis of slopes with general nonlinear failure criterion," International Journal for Numerical and Analytical Methods in Geomechanics, vol. 11, no. 1, pp. 33-50, 1987.

[10] E. Dawson, K. You, and Y. Park, "Strength-reduction stability analysis of rock slopes using the Hoek-Brown failure criterion," in Proceedings of the Sessions of Geo-Denver 2000 - Trends in Rock Mechanics, GSP 102, pp. 65-77, 2000.

[11] X.-L. Yang and J.-H. Yin, "Slope stability analysis with nonlinear failure criterion," Journal of Engineering Mechanics, vol. 130, no. 3, pp. 267-273, 2004. 
[12] A. J. Li, R. S. Merifield, and A. V. Lyamin, "Stability charts for rock slopes based on the Hoek-Brown failure criterion," International Journal of Rock Mechanics and Mining Sciences, vol. 45, no. 5, pp. 689-700, 2008.

[13] J. Shen and M. Karakus, "Three-dimensional numerical analysis for rock slope stability using shear strength reduction method," Canadian Geotechnical Journal, vol. 51, no. 2, pp. 164-172, 2014.

[14] Y. Gao, D. Wu, and F. Zhang, "Effects of nonlinear failure criterion on the three-dimensional stability analysis of uniform slopes," Engineering Geology, vol. 198, pp. 87-93, 2015.

[15] Y. Gao, D. Wu, F. Zhang et al., "Effects of nonlinear strength parameters on the stability of 3D soil slopes," Journal of Central South University, vol. 23, no. 9, pp. 2354-2363, 2016.

[16] L.-H. Zhao, X. Cheng, H.-C. Dan, Z.-P. Tang, and Y. Zhang, "Effect of the vertical earthquake component on permanent seismic displacement of soil slopes based on the nonlinear Mohr-Coulomb failure criterion," Soils and Foundations, vol. 57, no. 2, pp. 237-251, 2017.

[17] J. Xu and X. Yang, "Three-dimensional stability analysis of slope in unsaturated soils considering strength nonlinearity under water drawdown," Engineering Geology, vol. 237, pp. 102-115, 2018.

[18] E. Hoek, "Strength of jointed rock masses," Géotechnique, vol. 33, no. 3, pp. 187-223, 1983.

[19] E. Hoek, "Estimating Mohr-Coulomb friction and cohesion values from the Hoek-Brown failure criterion," International Journal of Rock Mechanics and Mining Sciences \& Geomechanics Abstracts, vol. 27, no. 3, pp. 227-229, 1990.

[20] E. Hoek and E. T. Brown, "Practical estimates of rock mass strength," International Journal of Rock Mechanics and Mining Sciences, vol. 34, no. 8, pp. 1165-1186, 1997.

[21] E. Hoek, C. Carranza-Torres, and B. Corkum, "Hoek-Brown failure criterion," in Proceedings of NARMS-Tac, pp. 267-273, 2002.

[22] P. Londe, " Discussion of " Determination of the Shear Failure Envelope in Rock Masses" by Roberto Ucar (March, 1986, Vol. 112, No. 3) ," Journal of Geotechnical Engineering, vol. 114, no. 3, pp. 374-376, 1988.

[23] P. Kumar, "Shear failure envelope of Hoek-Brown criterion for rockmass," Tunnelling and Underground Space Technology, vol. 13, no. 4, pp. 453-458, 1998.

[24] C. Carranza-Torres, "Some comments on the application of the HoekBrown failure criterion for intact rock and for rock masses to the solution of tunnel and slope excavation," in Proceedings of the Conference on Rock and Engineering Mechanics, pp. 285-326, Torino, Italy, 2004.

[25] S. D. Priest, "Determination of shear strength and threedimensional yield strength for the Hoek-Brown criterion," Rock Mechanics and Rock Engineering, vol. 38, no. 4, pp. 299-327, 2005.

[26] W. Fu and Y. Liao, "Non-linear shear strength reduction technique in slope stability calculation," Computers \& Geosciences, vol. 37, no. 3, pp. 288-298, 2010.

[27] J. Shen, S. D. Priest, and M. Karakus, "Determination of mohr-coulomb shear strength parameters from generalized hoek-brown criterion for slope stability analysis," Rock Mechanics and Rock Engineering, vol. 45, no. 1, pp. 123-129, 2012.

[28] X.-L. Yang and J.-H. Yin, "Linear mohr-coulomb strength parameters from the non-linear hoek-brown rock masses," International Journal of Non-Linear Mechanics, vol. 41, no. 8, pp. 1000-1005, 2006.
[29] A. Drescher and C. Christopoulos, "Limit analysis slope stability with nonlinear yield condition," International Journal for Numerical and Analytical Methods in Geomechanics, vol. 12, no. 3, pp. 341-345, 1988.

[30] R. L. Michalowski and A. Drescher, "Three-dimensional stability of slopes and excavations," Géotechnique, vol. 59, no. 10, pp. 839-850, 2009.

[31] Y. F. Gao, F. Zhang, G. H. Lei, and D. Y. Li, "An extended limit analysis of three-dimensional slope stability," Géotechnique, vol. 63, no. 6, pp. 518-524, 2013.

[32] Z. Y. Chen, "Random trials used in determining global minimum factors of safety of slopes," Canadian Geotechnical Journal, vol. 29, no. 2, pp. 225-233, 1992.

[33] H. T. Eid, "Stability charts for uniform slopes in soils with nonlinear failure envelopes," Engineering Geology, vol. 168, pp. 38-45, 2014.

[34] R. J. Chandler, "Lias clay: the long-term stability of cutting slopes," Géotechnique, vol. 24, no. 1, pp. 21-38, 1974.

[35] R. Baker, "Inter-relations between experimental and computational aspects of slope stability analysis," International Journal for Numerical and Analytical Methods in Geomechanics, vol. 27, no. 5, pp. 379-401, 2003. 


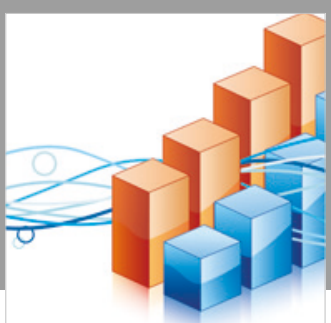

Advances in

Operations Research

\section{-n-m}
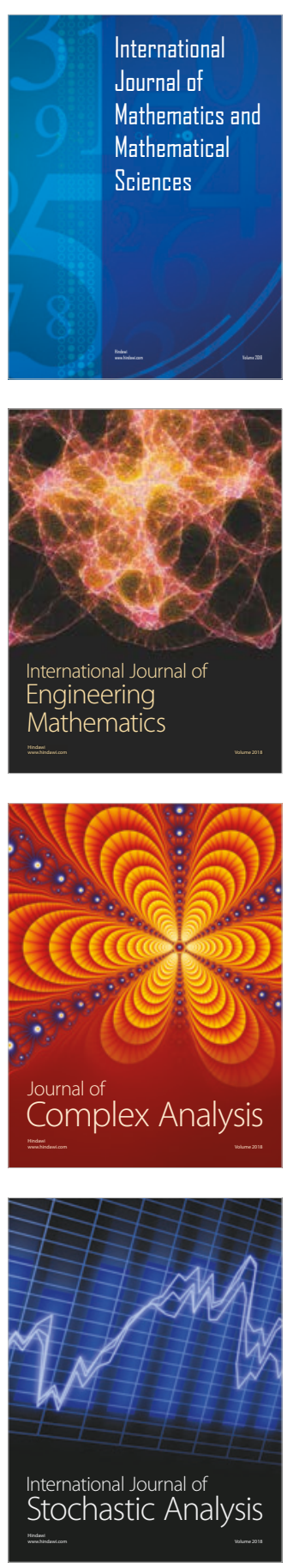
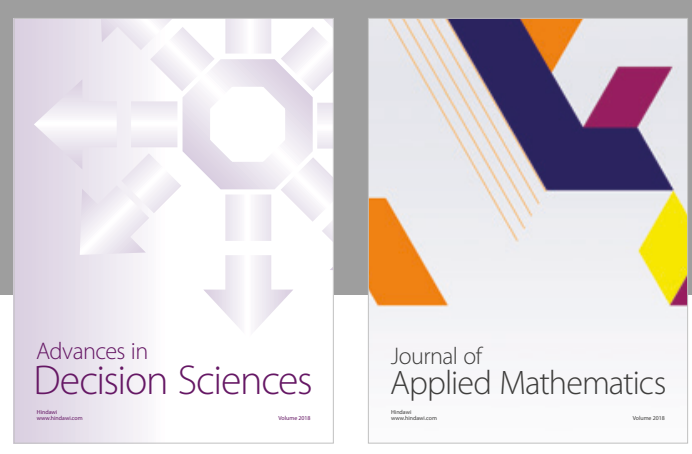

Journal of

Applied Mathematics
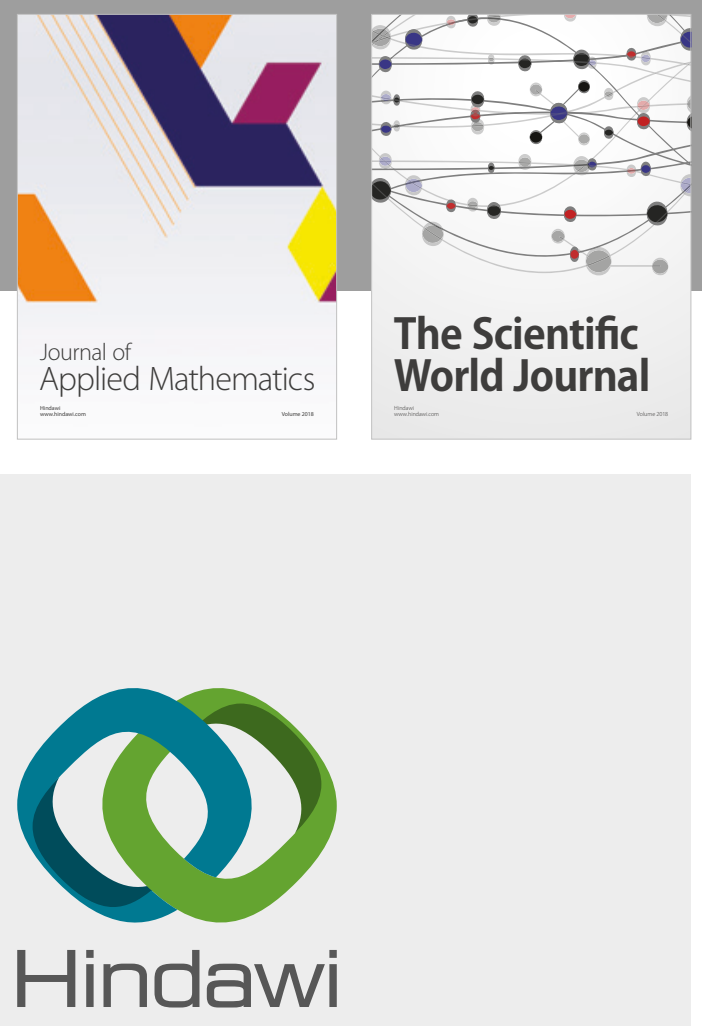

Submit your manuscripts at

www.hindawi.com

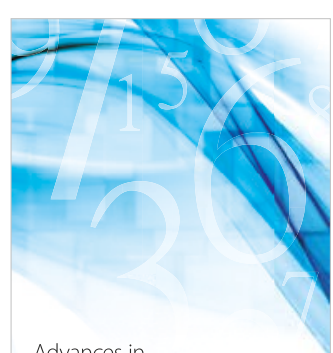

Advances in
Numerical Analysis
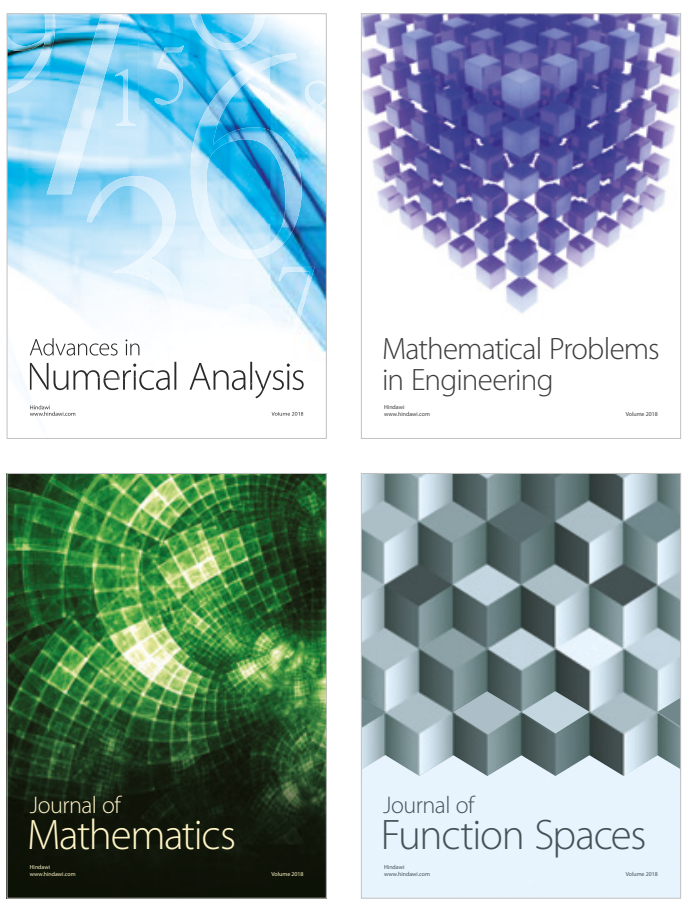

Mathematical Problems in Engineering

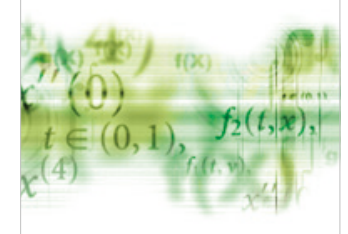

International Journal of

Differential Equations

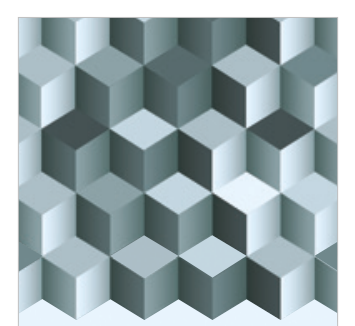

Journal of

Function Spaces

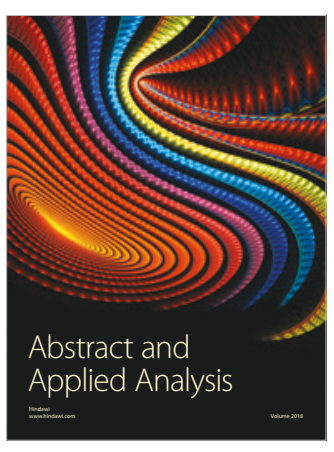

The Scientific

World Journal

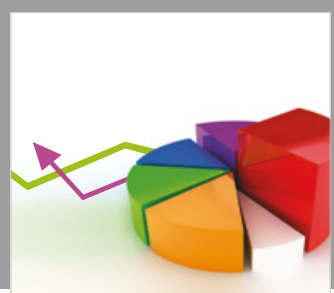

Journal of

Probability and Statistics
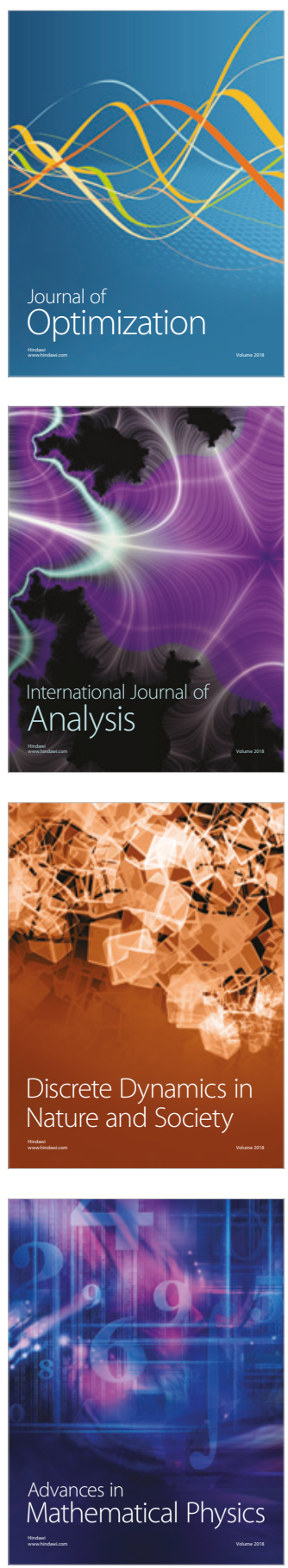